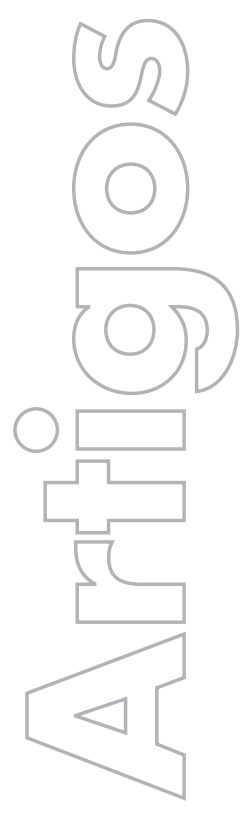

\title{
A pesca artesanal e a produção dos geógrafos brasileiros de meados do século XX
}

\section{Eduardo Schiavone Cardoso \\ UFSM}

\section{revista}

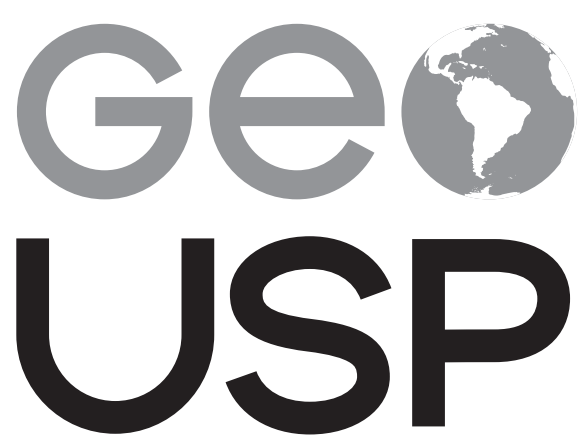

espaço e tempo

Volume $22 \cdot n^{\circ} 3$ (2018)
Como citar este artigo:

CARDOSO, E. S. A pesca artesanal e a produção dos geógrafos brasileiros de meados do século XX. Geousp - Espaço e Tempo (Online), v. 22, n. 3, p. 656-669, dez. 2018. ISSN 2179-0892.

Disponível em: <https://www.revistas.usp.br/geousp/article/view/144412>. doi: http://dx.doi.org/10.11606/issn.21790892.geousp.2018.144412.

\section{(c) (1) (\$)}

Este artigo está licenciado sob a Creative Commons Attribution 4.0 License. 


\title{
A pesca artesanal e a produção dos geógrafos brasileiros de meados do século $X X$
}

\section{Resumo}

Os objetivos deste trabalho são apresentar parte da produção dos geógrafos brasileiros de meados do século XX sobre a atividade pesqueira e analisar o quadro conceitual e empírico adotado nas análises do período. Pretende ainda verificar a atualidade das obras avaliadas e seus aspectos superados, contribuindo para o resgate da produção geográfica sobre o tema da atividade pesqueira, especialmente da chamada pesca artesanal.

Palavras-chave: Geografia. Pesca artesanal. Pescadores. Memória. Brasil.

\section{The artisan fishing and the work of Brazilian geographers from the middle of 20 th century}

\begin{abstract}
This study seeks to present part of the research work of Brazilian geographers from the middle of $20^{\text {th }}$ century regarding fishing activity, as well as to analyze the conceptual and empirical approaches employed in those researches. The study also examines both the applicability and obsolete aspects of those researches in the present day. Therefore, this investigation contributes to retrieving geography work about fishing activity, especially the artisan fishing.
\end{abstract}

Keywords: Geography. Artisan Fishing. Fishermen. Memory. Brazil.

\section{Introdução}

Apresentar parte da produção dos geógrafos brasileiros de meados do século XX sobre a atividade pesqueira e analisar os aportes conceituais e empíricos de tais obras são os objetivos do presente texto. Representa um esforço de resgatar tal produção, verificando sua atualidade e seus aspectos superados, contribuindo ainda para preservar a memória de parte da produção geográfica brasileira sobre a temática da pesca, em especial da chamada pesca artesanal. 
Consiste em uma nova contribuição que se acresce ao texto publicado em 2016, no Boletim Paulista de Geografia, intitulado "A pesca artesanal brasileira: passado e presente visitados a partir dos Tipos e Aspectos do Brasil", no qual o objetivo foi analisar as seções homônimas da Revista Brasileira de Geografia, ilustradas por Percy Lau, que tinham na atividade pesqueira a sua temática (Cardoso, 2016).

Consiste também, ainda que indiretamente, na continuidade do trabalho de análise da produção da Associação dos Geógrafos Brasileiros (AGB) dos anos 1940-1960, cujas publicações inventariaram a produção dos geógrafos sobre o estado do Rio Grande do Sul (Cardoso et al., 2011, 2015), além do e-book intitulado A Geografia do Rio Grande do Sul de meados do século XX: retratos do território e da produção da Associação dos Geógrafos Brasileiros, lançado pela Seção Porto Alegre da AGB, em que estão transcritas as obras selecionadas que versam sobre diversos aspectos da geografia gaúcha de então (Cardoso; De David, 2014).

Trazer à tona parte da produção dos geógrafos brasileiros sobre a atividade pesqueira das décadas em questão, permite atentar para a antiguidade com que esta temática permeia os estudos geográficos, aferir o tratamento conceitual e metodológico com que o tema foi abordado, constatar que tais artigos foram veiculados em distintas modalidades de difusão do conhecimento geográfico e manter a memória dos registros sobre a atividade pesqueira produzida pelos geógrafos, cotejando com a situação do setor pesqueiro contemporâneo.

\section{As fontes de pesquisa}

As obras a serem apresentadas e analisadas neste artigo foram pesquisadas na Revista Brasileira de Geografia, nos Anais da AGB e no arquivo de teses da Faculdade de Filosofia, Letras e Ciências Humanas (FFLCH) da Universidade de São Paulo (USP), tendo como recorte temporal as décadas de 1940-1960.

Buscou-se com tais opções abranger parte da produção dos vetores básicos da Geografia brasileira do século XX no dizer de Monteiro (2002, p. 4), a saber: "a Universidade como centro de produção; a Fundação IBGE como aplicação oficial e a Associação dos Geógrafos Brasileiros como refletor das tendências e conflitos na comunidade de geógrafos do Brasil".

Com relação ao período de análise, optou-se por essas três décadas porque abarcam o surgimento e a consolidação dos veículos de difusão da produção geográfica brasileira e representam ainda as décadas que antecedem ao processo de modernização conservadora do setor pesqueiro no Brasil, promovido pela Superintendência de Desenvolvimento da Pesca (Sudepe), criada no ano de 1962.

Duas teses da USP, cinco artigos publicados na Revista Brasileira de Geografia, dois trabalhos apresentados e publicados nos Anais da AGB e três relatórios de trabalho de campo produzido durante a Assembleia Anual da AGB de 1953, consistem no conjunto a ser objeto da análise (Quadros 1 a 4). 


\section{Quadro 1 - Obras selecionadas - teses}

título: Santos e a geografia humana do litoral paulista

autor: Maria Conceição Vicente de Carvalho

tese de doutoramento - USP - 1944

título: A ilha de São Sebastião: estudo de geografia humana

autor: Ary França

USP - 1954

\section{Quadro 2 - Obras selecionadas - Revista Brasileira de Geografia}

título: Geografia Humana do Brasil

autor: Pierre Deffontaines

Separata da Revista Brasileira de Geografia - n. 1-3 - ano 1 - 1940

título: A pesca no litoral do Rio de Janeiro

autores: Lysia Maria Cavalcanti Bernardes e Nilo Bernardes

Revista Brasileira de Geografia - v. 12 - n. 1 - 1950

título: Contribuição ao estudo da pesca na região do rio Arari (Ilha do Marajó)

autor: Maria Magdalena Vieira Pinto

Revista Brasileira de Geografia - v. 18 - n. 3 - 1956

título: Pescadores da Ponta do Caju: aspectos da contribuição de portuguêses e espanhóis para o

desenvolvimento da pesca na Guanabara

autor: Lysia Maria Cavalcanti Bernardes

Revista Brasileira de Geografia - v. 20 - n. 2 - 1958

título: contribuição geográfica ao estudo da pesca no litoral de Santa Catarina

autor: Paulo Fernando de Araújo Lago

Revista Brasileira de Geografia - v. 23 - n. 1 - 1961

\section{Quadro 3 - Obras selecionadas - anais da AGB}

título: Aspectos da atividade pesqueira em Pernambuco

autor: Hilton Sette

anais da AGB - v. XI - tomo I - 1957-1958

ano de publicação: 1959

título: Pescadores das ilhas da Guanabara

autor: Haidine da Silva Barros

anais da AGB - v. XIV - 1960-1962

ano de publicação: 1968

\section{Quadro 4 - Obras selecionadas - relatórios de trabalho de campo AGB}

título: Cuiabá - estudo de geografia urbana

autor: Aroldo de Azevedo

Anais da AGB - v. VII - tomo II - 1952/1953

ano de publicação: 1957

título: A zona rural de Cuiabá

autor: Pasquale Petrone

Anais da AGB - v. VII - tomo II - 1952/1953

ano de publicação: 1957

título: A região ribeirinha do médio Cuiabá - estudo de geografia humana

autor: Mário Lacerda de Melo

Anais da AGB - v. VII - tomo II - 1952/1953

ano de publicação: 1957 
Cabe ressaltar que a pesquisa realizada não é definitiva e outros materiais foram encontrados ao longo do processo, sendo deixados de lado no momento por não consistirem em materiais difundidos nos veículos selecionados, ou por serem produzidos por pesquisadores não geógrafos. É o caso do trabalho de Maria Conceição Vicente de Carvalho publicado na Revista do Arquivo Municipal em 1948, do trabalho de Carlos Borges Schmidt publicado pela Secretaria da Agricultura de São Paulo também em 1948, do Atlas Geográfico de Santa Catarina publicado pelo Conselho Nacional de Geografia em 1958, do trabalho de Clement de Bojano também publicado na Revista do Arquivo Municipal em 1940, das notas de pesquisa publicadas por Lysia Maria Cavalcanti Bernardes no Boletim da Seção Regional da AGB do Rio de Janeiro em 1949, do artigo de Ascânio de Faria publicado em 1960 na Revista Brasileira de Geografia, além de toda a obra da antropóloga Gioconda Mussolini produzida ao longo das décadas de 1940 e 1950, do trabalho de Câmara Cascudo - A Jangada e dos artigos publicados no periódico A Voz do Mar nas décadas de 1930 e 1940.

Ressalta-se também que não foram analisados os trabalhos apresentados ou produzidos durante as assembleias da AGB, que fazem breves referências à atividade pesqueira embutidas na análise de temas mais amplos, tais como o de Araújo Filho sobre os caiçaras de Itanhaém, publicado em 1953, o de Milton Santos sobre a cidade e o porto de Ituberá, publicado em 1958, e os relatórios coordenados por Pasquale Petrone sobre a Várzea do Açu e Carlos Augusto de Figueiredo Monteiro sobre o Baixo São Francisco, publicados respectivamente em 1961 e 1962.

\section{Sinopse da produção selecionada}

\section{As teses}

O trabalho de Maria Conceição Vicente de Carvalho representa o primeiro doutoramento defendido em Geografia no Brasil. Consiste em uma análise da cidade de Santos e da região litorânea paulista, com ênfase na Geografia Humana. Apresenta a discussão sobre a pesca dentro do capítulo "Os gêneros de vida do litoral" e inicia com a justificativa de que o pescador consiste no gênero de vida mais ligado ao meio local e também o mais livre da influência recente da civilização. Apresenta algumas características da costa brasileira em relação à produtividade pesqueira e alguns aspectos históricos do uso do pescado pelos indígenas brasileiros, para em seguida descrever os processos de pesca presentes no litoral paulista.

Destaca dois processos principais: o dos pescadores das praias que vivem da pesca próxima das localidades de moradia que pertencem a um gênero de vida ligado ao meio rural e a pesca moderna que realiza a pesca costeira e tem sede em Santos, onde vivem os tripulantes das embarcações pertencentes a um gênero de vida, de certo modo, urbano. A partir daí descreve os processos de pesca com destaque para a pesca de tainha e a pesca com lanchas, traineiras e arrastos.

Aponta dois processos de modernização da pesca engendrados por pescadores brasileiros - o advento das lanchas a motor e a industrialização da manjuba e a contribuição dos japoneses na introdução do cerco flutuante e das salgas de pescado, finalizando com um apontamento sobre as disputas entre o pequeno produtor de pescado e a indústria de pesca nascente.

trabalho de Ari França busca analisar a llha de São Sebastião em suas características geográficas e de ecologia humana, verticalizando o estudo na planície do Perequê e consiste em tese da cátedra defendida pelo autor. Trata da atividade pesqueira dentro do capítulo intitu- 
lado "A vida humana na ilha de São Sebastião" e destaca a linha costeira recortada da ilha favorecendo o surgimento de gêneros de vida ligados ao mar, pois consiste em uma das principais áreas de pesca comercial da costa meridional brasileira.

Identifica 175 pescadores profissionais na ilha em 1950, que pescavam nas traineiras e nos cercos flutuantes (Figura 1) e identifica a atividade de traineiras de outros centros pesqueiros e barcos que compram a produção dos pescadores locais para abastecer os mercados de Santos ou Rio de Janeiro. Contabiliza 30 cercos instalados cuja introdução na ilha por japoneses remonta ao ano de 1919, além das salgas de propriedade de japoneses e de uma fábrica de gelo.

O autor aponta o empirismo, a improvisação e a insegurança com os quais os profissionais da pesca convivem, afirmando que os pescadores desconhecem o regime das águas e a biologia das espécies. Por outro lado, constata a captura de 106 espécies de pescado diferenciadas e refere-se às técnicas avançadas da pesca comercial dos cercos e das traineiras. Quanto às demais modalidades de pesca, o autor considera providas de baixo emprego técnico e com resultados medíocres.

\section{Figura 1 - Mapa dos equipamentos de pesca na Ilha de São Sebastião}

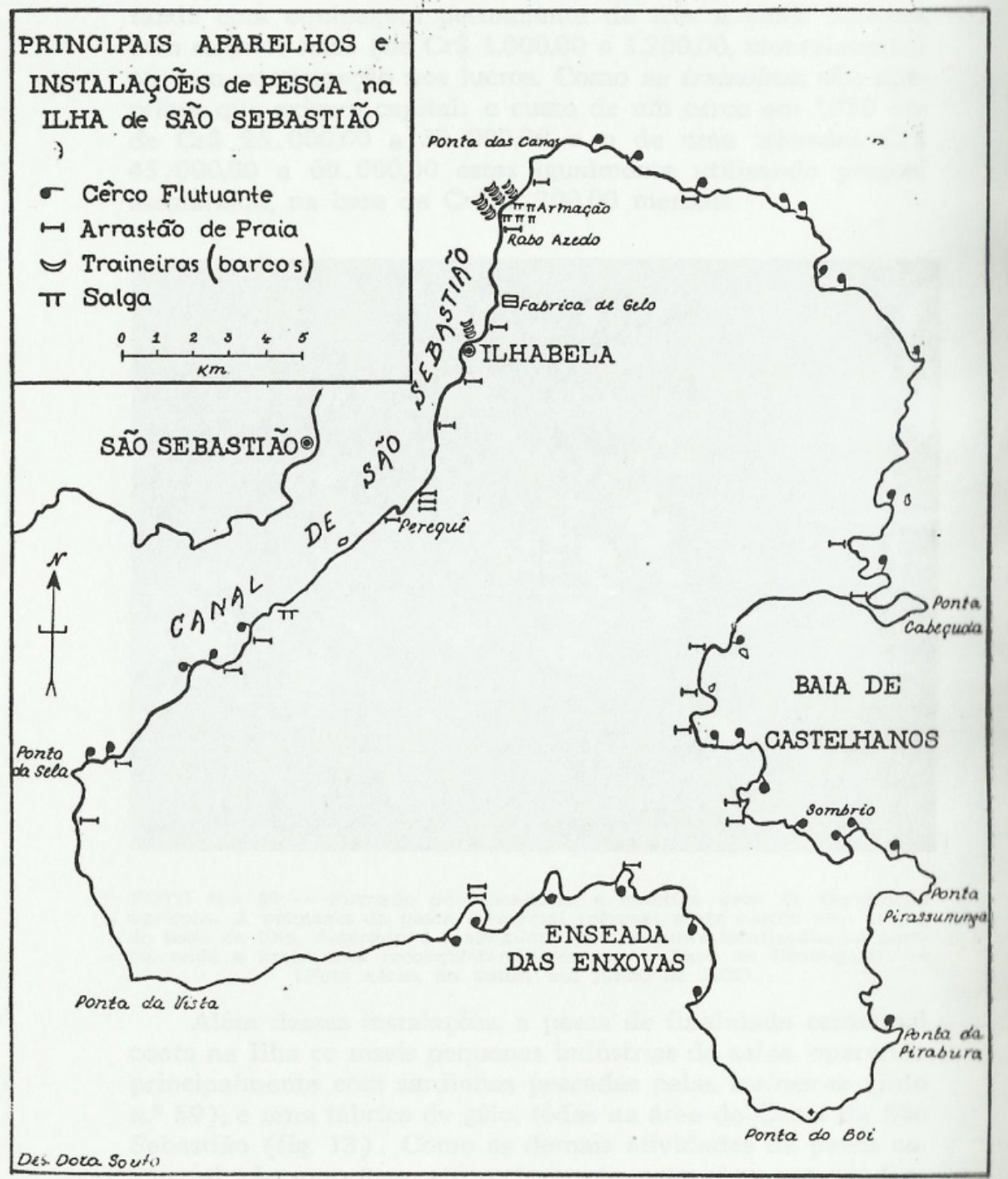

fonte: França (1954). 


\section{Os artigos da Revista Brasileira de Geografia}

O trabalho de Pierre Deffontaines traça a "Geografia humana do Brasil" e foi publicado como separata da Revista Brasileira de Geografia em 1940. Trata da atividade pesqueira em dois momentos, o primeiro atrelado à análise do litoral brasileiro e o segundo como uma das atividades econômicas desenvolvidas no território (Figura 2).

No primeiro momento pontua alguns elementos do histórico da pesca no Brasil desde os povos pré-colombianos até a pesca de baleia promovida pelos colonizadores portugueses, para refletir sobre a importância do pescado na vida das populações litorâneas. No segundo momento, aponta os problemas gerais da pesca brasileira, ressaltando a riqueza da ictiofauna marinha e fluvial que contrasta com os processos pouco desenvolvidos da pesca, apesar da herança pesqueira lusitana, que culmina com a necessidade de importar pescado.

\section{Figura 2 - Pescadores de Cabo Frio em foto de S. Fróis Abreu}

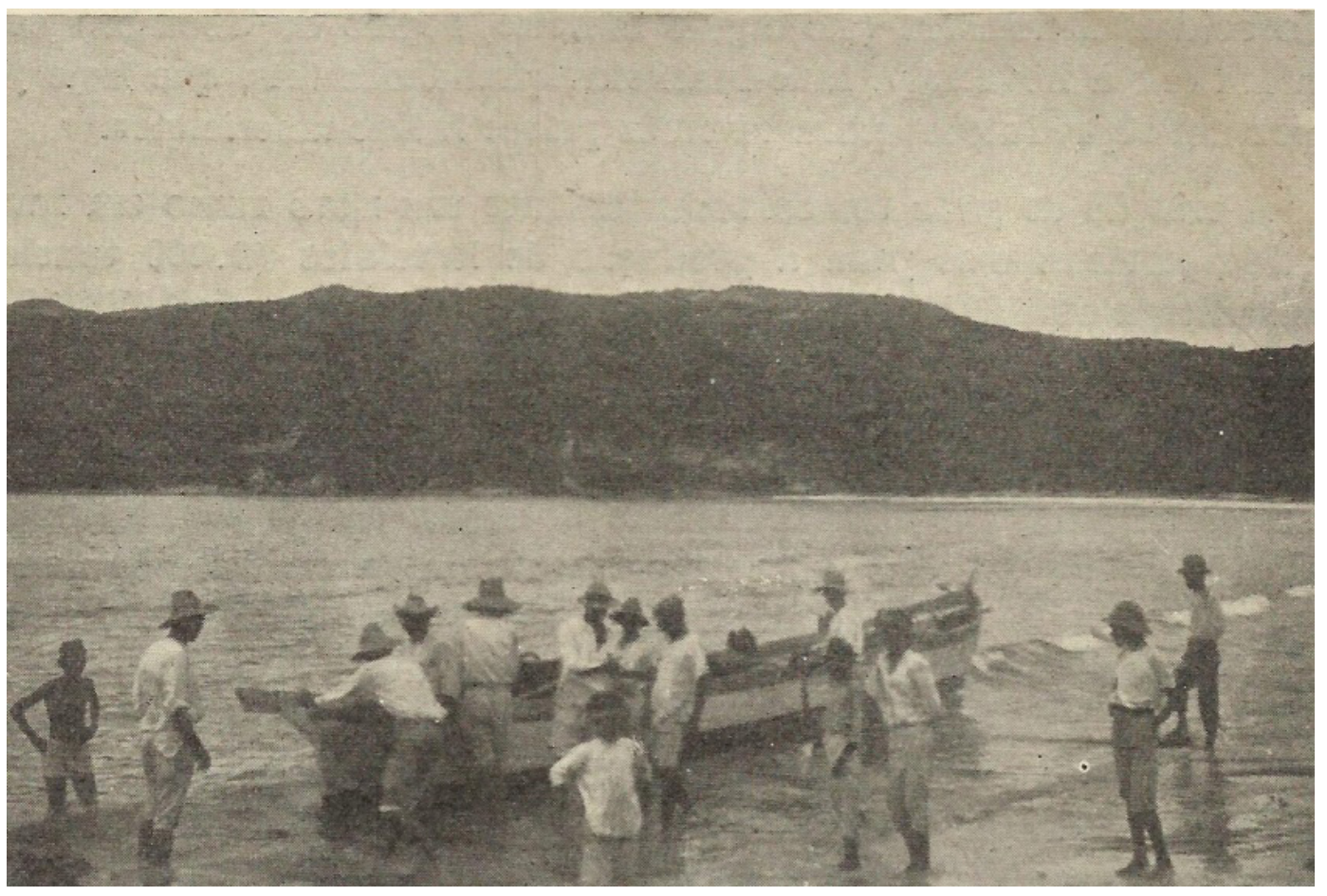

fonte: Deffontaines (1940).

O trabalho do casal Lysia Maria Cavalcanti Bernardes e Nilo Bernardes intitulado "A pesca no litoral do Rio de Janeiro", publicado em 1950 é uma descrição bastante detalhada da atividade pesqueira marinha fluminense. $O$ ponto de partida é a análise dos processos de pesca das águas interiores e costeiras, descrevendo as modalidades e instrumentos de captura de forma detalhada, acompanhada de ilustrações dos próprios autores (Figura 3).

A segunda seção do trabalho analisa os gêneros de vida e a distribuição espacial dos pescadores do Rio de Janeiro distinguindo os habitantes das restingas e os das encostas rochosas, mapeando o número de pescadores no estado e distinguindo os chamados muxuangos - habitantes das planícies do norte do estado, dos caiçaras - residentes no sul, onde estão presentes as serras e costões litorâneos. Os autores concluem apontando as contradições da atividade pesqueira, os métodos ainda primitivos e alguns processos de modernização da atividade em curso. 


\section{Figura 3 - Pesca de cerco de emalhar em desenho de Nilo Bernardes}

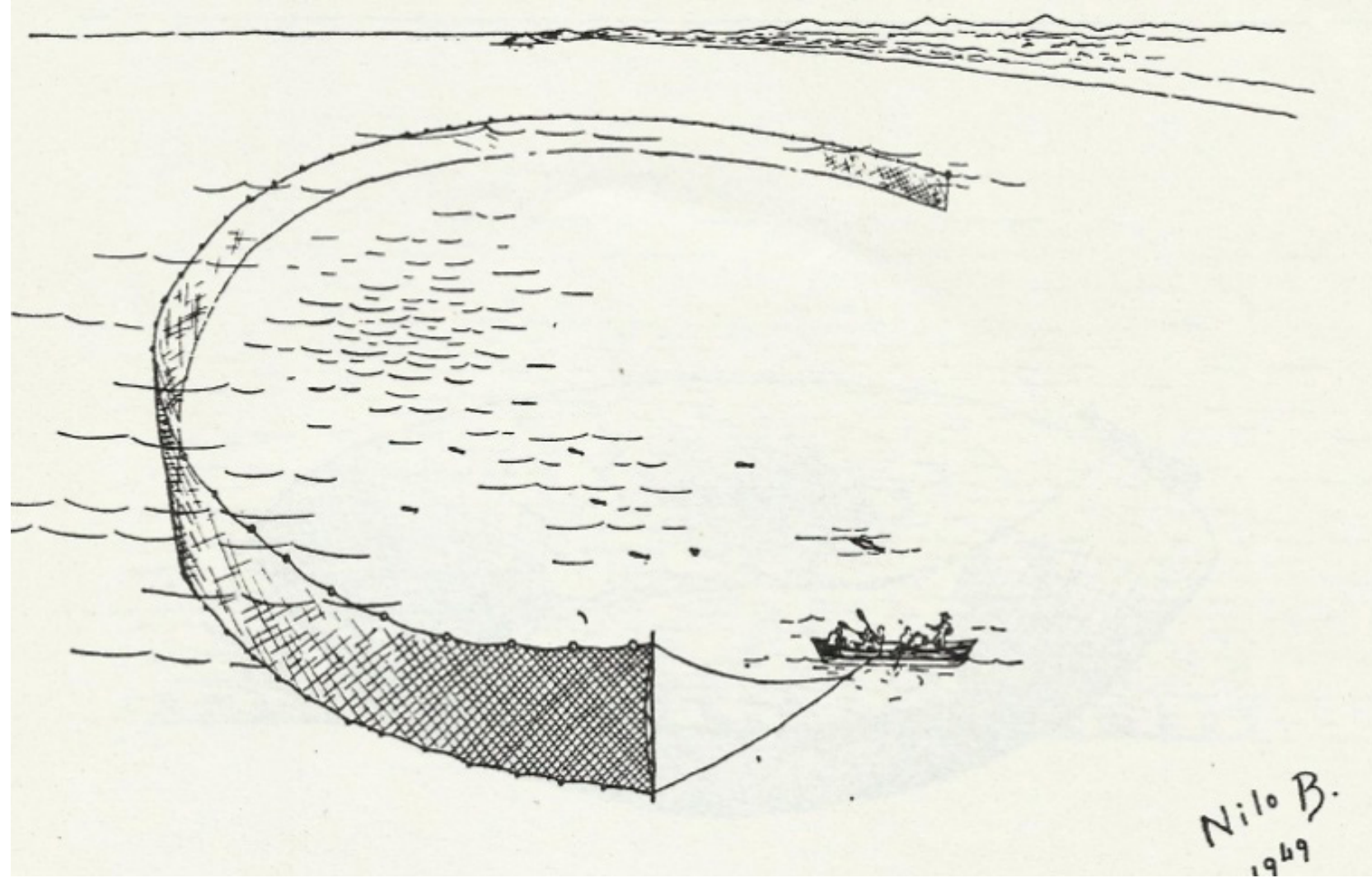

fonte: Bernardes e Bernardes (1950).

O trabalho de Maria Magdalena Vieira Pinto retrata a atividade pesqueira na região do Lago Arari, na Ilha do Marajó. Inicia diferenciando a pesca flúvio-lacustre da região em grande e pequena pesca, sendo a grande pesca - aquela destinada ao comércio - o objeto de estudo do artigo. Subdivide a análise tratando das épocas de pesca no Marajó, os processos e materiais de pesca (Figura 4), o beneficiamento e o comércio do pescado, a industrialização e finaliza tratando das colônias de pescadores e do gênero de vida dos mesmos.

A época de pesca vai de 15 de agosto a 15 de dezembro, quando o lago é fechado segundo o Código de Pesca, sendo que os pescadores obtém uma prorrogação de três meses até março, um período favorável à pesca mas que prejudica a procriação das espécies. A autora realiza uma descrição dos vários métodos de pesca e suas variações locais, para depois descrever o processo de comercialização do peixe fresco, congelado e beneficiado pelos processos de salga, apresentando toda a rede de intermediação entre o pescador e o consumidor. Analisa também os processos de industrialização do pescado, com destaque para o chamado "grude" da gurijuba.

Finaliza o artigo analisando as colônias de pescadores locais, e os conflitos que se estabelecem entre pescadores e fazendeiros pelo acesso às áreas de pesca, além do problema do transporte que submete os pescadores aos meios de intermediação. 


\section{Figura 4 - Pesca de tarrafa no Rio Arari em desenho de Barbosa Leite}
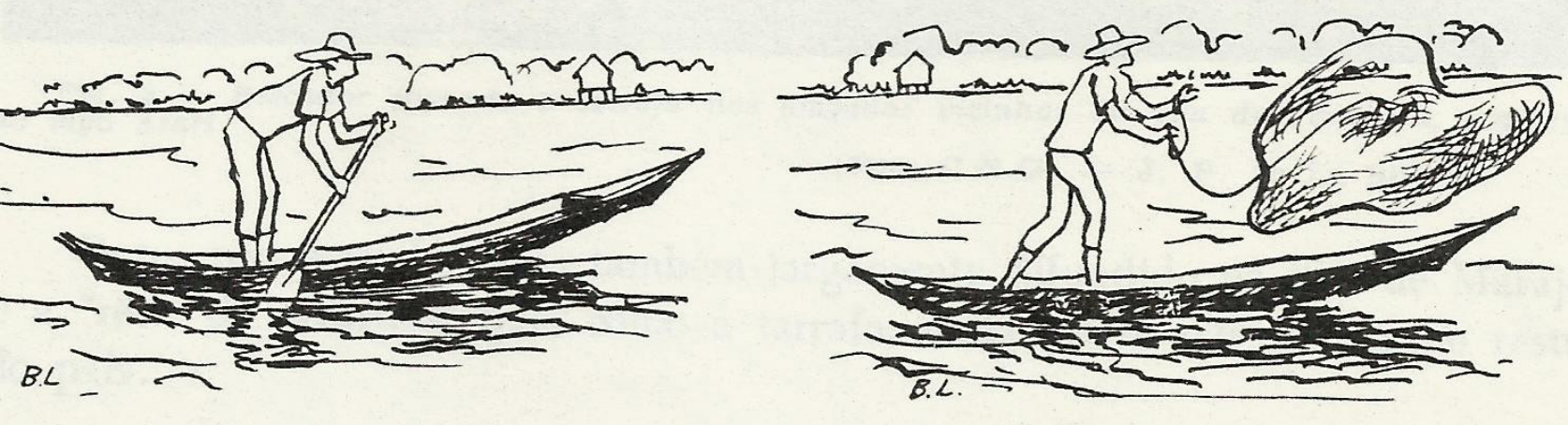

fonte: Pinto (1956).

Em "Pescadores da Ponta do Cajú - Aspectos da Contribuição de Portugueses e Espanhóis para o Desenvolvimento da Pesca na Guanabara", Lysia Bernardes desenvolve o texto em três partes principais. Inicia fazendo um apanhado geral dos agrupamentos de pescadores da Guanabara, destacando as praias, ilhas e as áreas urbanas, como a Ponta do Cajú. Nos núcleos urbanos destaca a presença de portugueses e espanhóis entre os trabalhadores da pesca.

Na segunda parte do texto, aponta a origem e o crescimento do núcleo de pescadores do Cajú, bem como as transformações espaciais dessa área urbana do Rio de Janeiro, com a urbanização e os aterros. A última parte do texto destaca a contribuição dos pescadores ibéricos na modernização e industrialização dos processos de pesca, retratando a introdução da pesca de camarão com arrasto e a pesca de sardinha com as traineiras, ambas inovações tecnológicas trazidas por pescadores espanhóis e portugueses.

trabalho de Paulo Fernando de Araújo Lago, intitulado "Contribuição Geográfica ao Estudo da Pesca no Litoral de Santa Catarina" é uma caracterização da pesca catarinense que abrange aspectos físicos, históricos, econômicos e sociais. Inicia apontando as características climáticas e geomorfológicas do litoral de Santa Catarina destacando as relações destas características com os aglomerados de pescadores e os processos de pesca, para em seguida tratar do povoamento do litoral e da colonização açoriana, que marca a origem dos núcleos pesqueiros.

Após essas duas seções, o autor analisa a população pesqueira do litoral, a partir da distribuição demográfica, das atividades pesqueiras e dos tipos humanos, diferenciando o camarada, o proprietário dos meios de produção, o intermediário e outros tipos como o fazedor de rede, o canoeiro e o industrial. Nas seções finais, são analisadas as técnicas e os processos de pesca, as zonas e os núcleos pesqueiros, a indústria da pesca e a produção da pesca catarinense.

\section{Os trabalhos apresentados nos anais da AGB}

$\bigcirc$ trabalho de Hilton Sette sobre a atividade pesqueira pernambucana inicia com uma análise da paisagem litorânea, na qual a presença do coqueiro e a jangada expõem formas indicativas da ocupação humana. $\bigcirc$ autor estabelece as relações entre estas duas atividades eco- 
nômicas - a pesca de jangada (Figura 5) e a monocultura do coco, desvelando as articulações entre o pescador que vive de favor na beira da praia ou é um pequeno sitiante e o proprietário fundiário das fazendas.

Em seguida analisa as características da pesca artesanal pernambucana, sua adaptação ao ambiente e seus processos taxados como primitivos pelo autor, bem como os processos de comercialização do pescado. À pesca artesanal o autor contrapõe a pesca industrial do atum, que se implanta em Pernambuco a partir da Indústria Brasileira do Peixe (Inbrape), que apesar do nome é dirigida por técnicos japoneses e tem atuado na captura e industrialização do atum, contribuindo para o aumento da oferta de pescado. Finaliza com observações referentes ao baixo preço do atum industrializado e o pescado mais valorizado produzido pela pesca artesanal.

\section{Figura 5 - Jangada retornando de alto mar em foto de Oscar Maia}

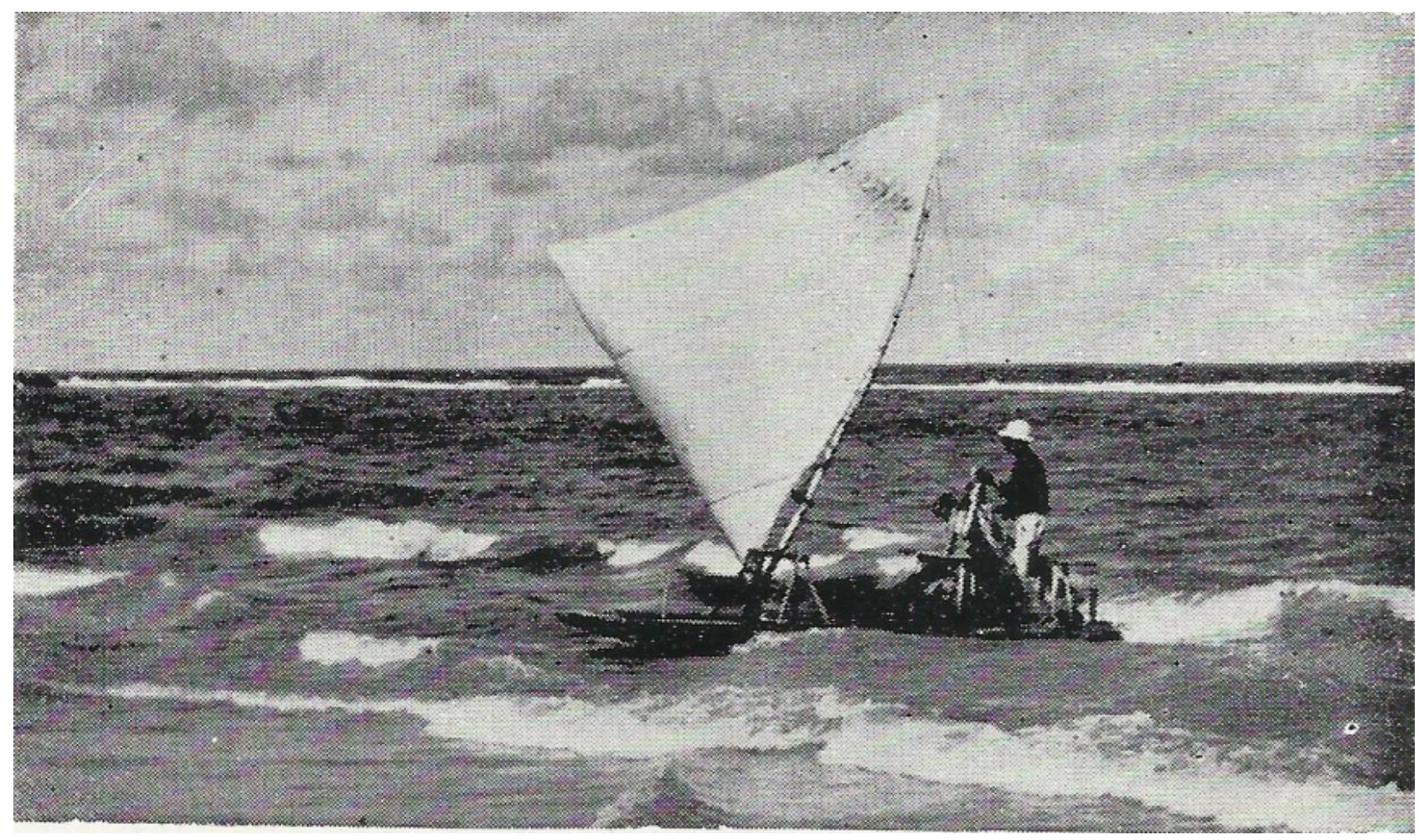

fonte: Sette (1959).

O trabalho de Haidine da Silva Barros descreve a pesca e os pescadores das llhas da Conceição e do Governador na Baia de Guanabara, fazendo inicialmente um contraponto com o artigo de Lysia Bernardes sobre a presença de pescadores portugueses e brasileiros na pesca das ilhas em questão. Em seguida a autora caracteriza os núcleos pesqueiros das ilhas da Conceição e do Governador (Figura 6) e descreve os processos de pesca identificados como tradicionais e que empregam técnicas primitivas e pouco lucrativas.

Nas seções seguintes distingue os pescadores brasileiros e portugueses residentes nas ilhas, com relação aos métodos de pesca e as formas de comercialização da produção do pescado e finaliza traçando considerações sobre o desenvolvimento futuro da pesca nas localidades em questão. 


\section{Figura 6 - Rede de cerco a secar na Praia do Galeão - Ilha do Governador}

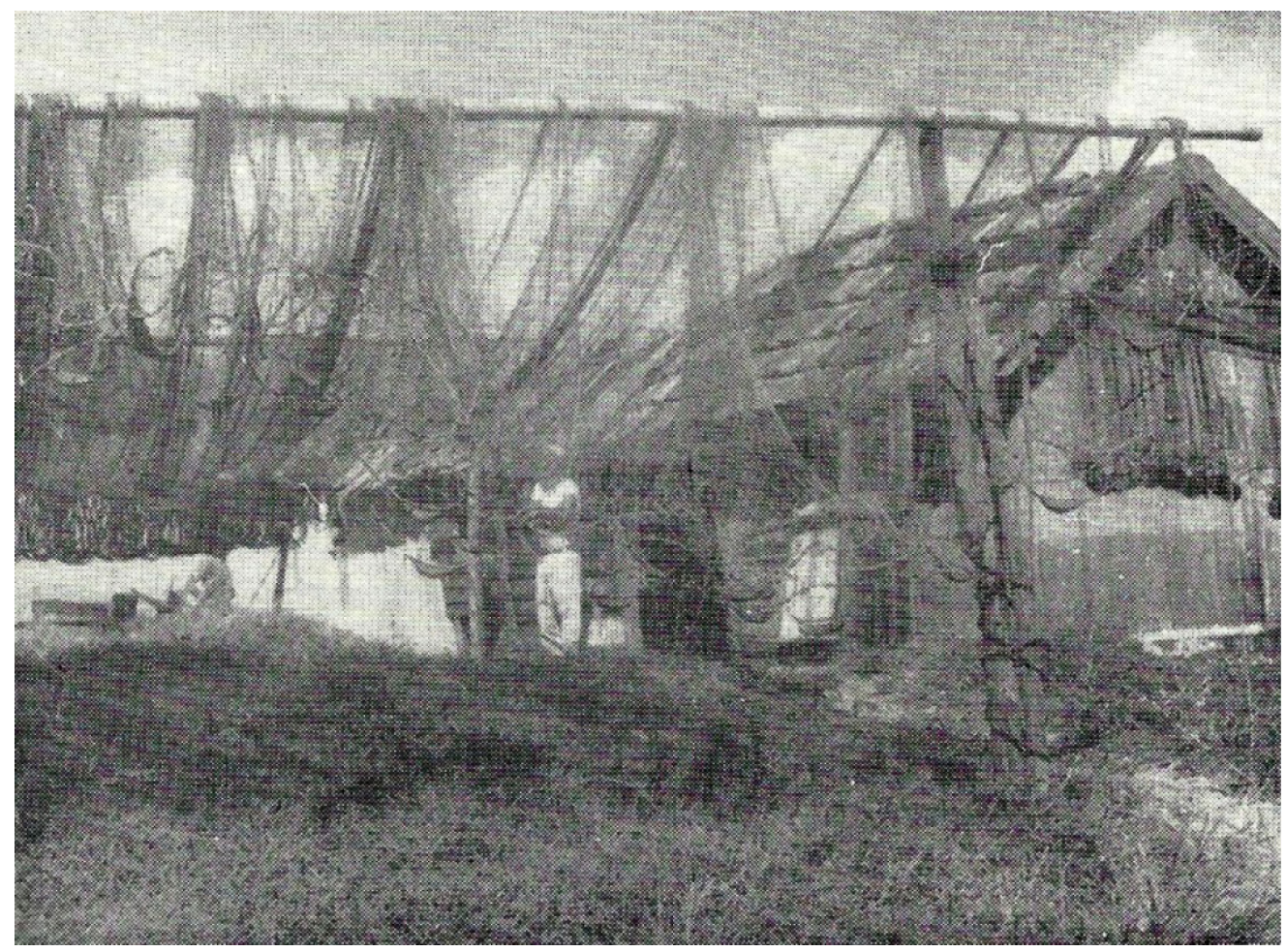

fonte: Barros (1968).

\section{Os relatórios dos trabalhos de campo da AGB}

Nos anos de 1940, 1950 e 1960, as Assembleias Anuais da AGB eram acompanhadas por trabalhos de campo nas cidades e arredores das sedes dos eventos. Os relatórios apresentados eram publicados sob a forma de Tomos ou Avulsos dos Anais das Assembleias. Os três textos selecionados são seções dos relatórios de trabalho de campo realizados por ocasião da VIII Assembleia da AGB realizada em Cuiabá, no ano de 1953 e publicados em 1957.

O relatório apresentado por Aroldo de Azevedo intitula-se "Cuiabá: um estudo de Geografia Urbana" e traz uma seção em que analisa a pesca fluvial do Rio Cuiabá, destacando o porto pesqueiro da cidade e o Mercado do Peixe com 92 pescadores inscritos oriundos das localidades próximas. Identifica ainda as espécies e épocas do pescado, bem como as outras formas de comercialização do peixe.

O relatório de Pasquale Petrone refere-se à Zona Rural de Cuiabá e apresenta a importância do Rio Cuiabá na vida rural do município, descrevendo as características e épocas da pesca, as técnicas de pesca e de conservação do pescado empregadas e as formas de comercialização, centralizadas no mercado municipal.

O relatório apresentado por Mario Lacerda de Melo intitula-se A Região Ribeirinha do Médio Cuiabá - Estudo de Geografia Humana e reporta-se a pesca praticada no pantanal diferenciando dois subsetores da planície do médio Cuiabá, com sistemas de pesca diferenciados. Ao norte, caracterizam-se dois períodos - a pesca na vazante e no começo das enchentes, em que o emprego das redes é característico, e ao sul, que se caracteriza como uma área de pesca de linha e anzol (Figura 7). Finaliza enfatizando a importância do pescado na alimentação ribeirinha e a produção de óleo de peixe. 


\section{Figura 7 - Abrigo para pesca no pantanal}

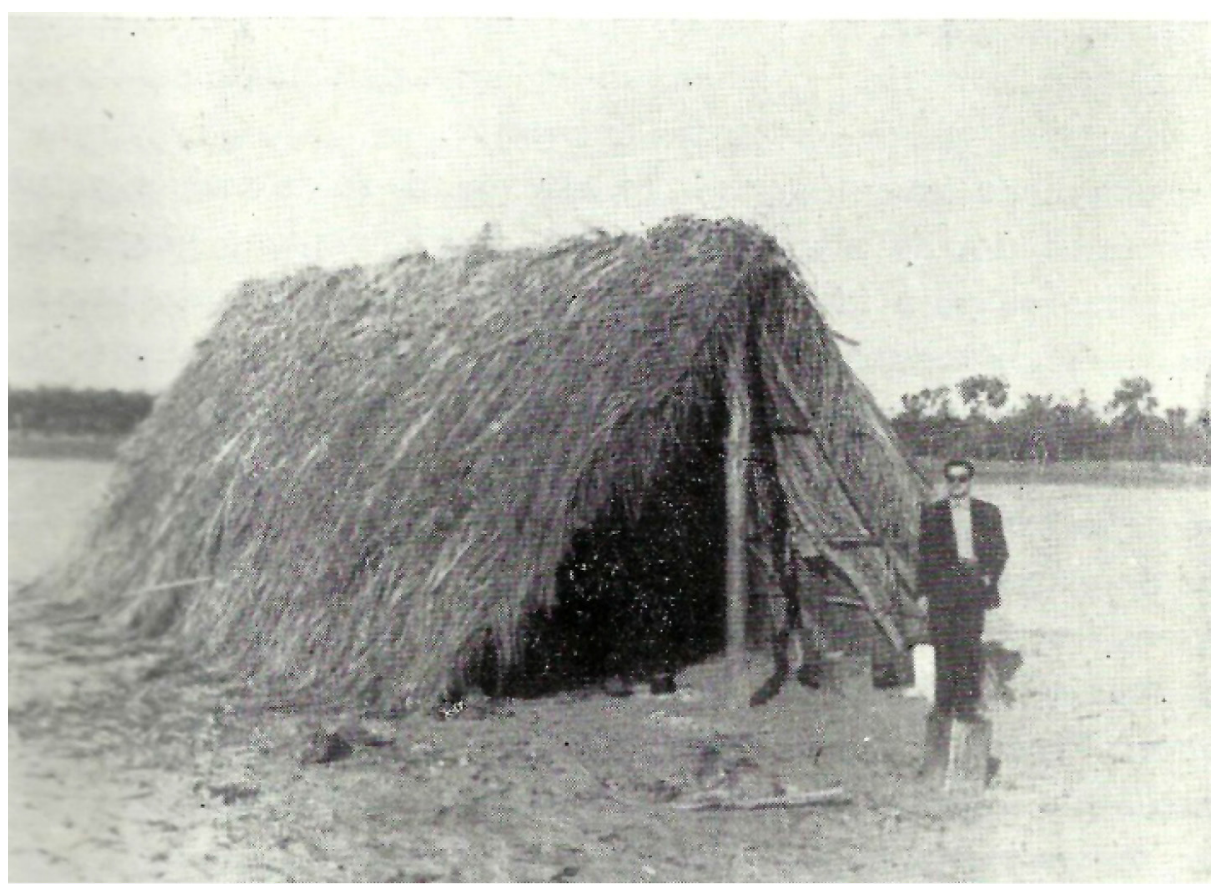

fonte: Melo (1957).

\section{A pesca artesanal e os aportes das obras elencadas}

Após a apresentação dos trabalhos selecionados serão tecidas algumas considerações a respeito do tratamento da atividade pesqueira engendrado pelos geógrafos de meados do século $X X$. Antes, porém, cabem algumas questões de âmbito geral referentes ao conjunto dos textos.

A primeira delas é que abarca estudos de caso de todas as cinco macrorregiões brasileiras atuais. É certo que há uma concentração de estudos no Sudeste brasileiro, em especial nos estados do Rio de Janeiro e São Paulo, que se justifica pela proximidade com os centros universitários e de gestão do território de então, mas a amostragem selecionada contempla obras que tratam da realidade pesqueira de localidades das regiões Norte, Nordeste, Centro-Oeste, Sudeste e Sul do país, demonstrando a iniciativa e o intuito de conhecer o território brasileiro em seus distintos aspectos e em sua totalidade.

Também como aspecto geral, observa-se que a atividade pesqueira é analisada em confrontação com os aspectos físicos, biológicos, econômicos, históricos, sociais, tanto em realidades agrárias como urbanas, litorâneas ou ribeirinhas, demonstrando a especificidade da pesca em relação ao espaço geográfico.

terceiro aspecto geral é a diversidade das modalidades de publicação do conjunto selecionado. São teses, artigos e relatórios de trabalhos de campo que contemplam a atividade pesqueira de modo central ou secundário, mas que apontam a existência e a importância desse setor produtivo e tornam-se referências para os estudos posteriores.

Outra questão destaca a incidência dos trabalhos de campo como metodologia de apreensão dos dados e a descrição como forma de aproximação com o objeto de estudo. Tais procedimentos coerentes com a geografia produzida de então, promovem uma leitura dos fatos que permite vislumbrar suas características na época que foram descritos, bem como observar algumas contradições presentes nas localidades pesquisadas. 
Finalmente observa-se a presença das imagens como forma de exposição das informações. Sejam fotografias, quadros, gráficos, desenhos, mapas ou esquemas interpretativos, o recurso a ilustrações é uma constante nos trabalhos elencados, concorrendo para uma maior aproximação do leitor com a realidade descrita e uma leitura mais dinâmica dos trabalhos.

Como aspectos específicos dos textos analisados, destacam-se o quadro conceitual e a circunstância histórica em que as obras foram produzidas. Nesse sentido o conceito de Gênero de Vida permeia a maior parte dos trabalhos selecionados. Tal conceito denota a influência da geografia francesa nos primórdios da produção da geografia brasileira e representa uma possibilidade de sistematização dos grupos humanos ligados à atividade pesqueira, que se diferenciam social, econômica e culturalmente.

Tais gêneros de vida ligados à pesca são descritos como simplórios ou primitivos, que têm um arsenal técnico tradicional. É aí que reside o segundo aspecto da análise específica, que é a circunstância histórica do conjunto trabalhado. Predominava nas décadas de 1940, 1950 e 1960 a pesca artesanal em todo o território brasileiro, com alguns pontos de modernização, tais como o litoral sudeste e partes do litoral sul e nordeste. Assim os trabalhos realizam a correlação entre gêneros de vida tradicionais e técnicas rudimentares ao descrever as realidades pesquisadas. Assumem também uma perspectiva política ao proporem a modernização e industrialização da pesca como a solução das mazelas observadas.

Fato presente nos discursos de então, o processo de modernização e industrialização da pesca brasileira será promovido pelo Estado em associação ao capital, a partir da Sudepe, nos anos 1960, cujas consequências para o setor são analisadas por Diegues (1983) e Cardoso (2001), entre outros. Um processo efêmero e predatório que marcou as décadas posteriores e do qual a pesca artesanal resistiu e persistiu, sendo apontada como a mais compatível com a preservação dos recursos pesqueiros no limiar do século XXI.

Qual seja, são justamente aqueles gêneros de vida tradicionais e primitivos, os esteios para o futuro da atividade pesqueira, em um processo de atualização tecnológica, rearranjos econômicos e de uso do espaço geográfico que implicam em conflitos territoriais, abrindo novas frentes de investigação para a geografia contemporânea na análise da atividade pesqueira.

\section{Considerações finais}

conjunto das obras selecionadas apresenta ao mesmo tempo um esforço para o entendimento da pesca brasileira e uma amostra da produção geográfica de meados do século XX. Produzido com os instrumentos teóricos e metodológicos da época, pode ser considerado clássico, pois retrata um momento específico do fenômeno estudado, possibilitando traçar sua evolução temporal e sua diferenciação espacial.

Reflete a dinâmica da comunidade geográfica brasileira com seus eventos, seus trabalhos de campo, seus veículos de difusão e suas temáticas de pesquisa. Com relação a este ponto, apresenta a atividade pesqueira como uma temática de interesse geográfico, com uma temporalidade bastante longa, posto que quase coincidente com a implantação dos três vetores do conhecimento geográfico brasileiro do século XX - as universidades, o Instituto Brasileiro de Geografia e Estatística (IBGE) e a AGB. Contribui, assim, para dirimir a estranheza em relação aos estudos da atividade pesqueira em sua dimensão geográfica. 


\section{Referências}

ARAUJO FILHO, J. R. O caiçara na região de Itanhaém. Anais da Associação dos Geógrafos Brasileiros. São Paulo, v. 3, tomo 1, p. 106-116, 1953.

AZEVEDO, A. Cuiabá: estudo de geografia urbana. Anais da Associação dos Geógrafos Brasileiros. São Paulo, v. 7, tomo 2, p. 13-66, 1957.

BARROS, H. S. Pescadores das ilhas da Guanabara. Anais da Associação dos Geógrafos Brasileiros. São Paulo, v. 14, p. 79-101, 1968.

BERNARDES, L. M. C. Pescadores da Ponta do Cajú: aspectos da contribuição de portugueses e espanhóis para o desenvolvimento da pesca na Guanabara. Separata da Revista Brasileira de Geografia, Rio de Janeiro, 1959.

BERNARDES, L. M. C. Notas sobre o desenvolvimento da pesca no litoral do Rio de Janeiro. Boletim da Seção Regional do Rio de Janeiro da AGB, Rio de Janeiro, v. 2, n. 1, p. 4-7, 1949.

BERNARDES, L. M. C.; BERNARDES, N. A pesca no litoral do Rio de Janeiro. Revista Brasileira de Geografia, Rio de Janeiro, v. 12, n. 1, p. 17-53, 1950.

BOJANO, C. O problema do pescado na cidade de São Paulo. Revista do Arquivo Municipal, São Paulo, v. VI, v. LXVIII, p. 31-77, 1940.

CARDOSO, E. S. A pesca artesanal brasileira: passado e presente visitados a partir dos "Tipos e Aspectos do Brasil". Boletim Paulista de Geografia, São Paulo, v. 94, p. 32-46, 2016.

CARDOSO, E. S. Os boletins das seções regionais da AGB de meados do século XX e a geografia do Rio Grande do Sul. Boletim Gaúcho de Geografia, Porto Alegre, v. 42, p. 84-93, 2015.

CARDOSO, E. S. Pescadores artesanais: natureza, território, movimento social. Tese (Doutorado em Geografia Humana) - Faculdade de Filosofia, Letras e Ciências Humanas, Universidade de São Paulo, São Paulo, 2001.

CARDOSO, E. S.; ALTERMANM, S.; BEZ, M.; DOTTO, B. C. A produção da Associação dos Geógrafos Brasileiros em meados do século XX e os estudos de geografia do Rio Grande do Sul. Geografia, Ensino \& Pesquisa, Santa Maria, v. 15, p. 217-226, 2011.

CARDOSO, E. S.; DAVID, C. (Org.). A geografia do Rio Grande do Sul em meados do século XX: retratos do território e da produção da Associação dos Geógrafos Brasileiros. Porto Alegre: AGB, 2014.

CARVAlHO, M. C. V. O pescador no litoral leste do estado de São Paulo. Revista do Arquivo Municipal, São Paulo, v. 9, n. 92, p. 37-46, 1948.

CARVALHO, M. C. V. Santos e a geografia humana do litoral paulista. Tese (Doutorado em Geografia Humana) - Faculdade de Filosofia, Ciências e Letras, Universidade de São Paulo, São Paulo, 1944. 
CASCUDO, L. C. Jangada: uma pesquisa etnográfica. 2a ed. Rio de Janeiro: Letras e Artes, 1964.

DEFFONTAINES, P. Geografia humana do Brasil. Separata da Revista Brasileira de Geografia. Rio de Janeiro, 1940.

DEPARTAMENTO ESTADUAL DE GEOGRAFIA E CARTOGRAFIA. Atlas Geográfico de Santa Catarina. Florianópolis: CNG, 1958.

DIEGUES, A. C. S. Pescadores, camponeses e trabalhadores do mar. São Paulo: Ática, 1983.

FARIA, A. A pesca e seus problemas. Revista Brasileira de Geografia, Rio de Janeiro, v. 22, n. 2, p. 149-161, 1960.

FRANÇA, A. A ilha de São Sebastião: estudo de geografia humana. São Paulo, USP, 1954.

LAGO, P. F. A. Contribuição geográfica ao estudo da pesca no litoral de Santa Catarina. Revista Brasileira de Geografia, Rio de Janeiro, v. 23, n. 1, p. 121-215, 1961.

MELO, M. L. A região ribeirinha do médio Cuiabá: estudo de geografia humana. Anais da Associação dos Geógrafos Brasileiros, São Paulo, v. 7, Tomo 2, p. 163-256, 1957.

MONTEIRO, C. A. F. A geografia no Brasil ao longo do século XX: um panorama. São Paulo: AGB, 2002.

MONTEIRO, C. A. F. (Org.). Aspectos geográficos do Baixo São Francisco. São Paulo: AGB, 1962. v. 5.

MUSSOLINI, G. Ensaios de antropologia indígena e caiçara. Rio de Janeiro: Paz e Terra, 1980.

PETRONE, P. A zona rural de Cuiabá. Anais da Associação dos Geógrafos Brasileiros. São Paulo, v. 7, tomo 2, p. 67-160, 1957.

PINTO, M. M. V. Contribuição ao estudo da pesca na região do rio Arari (Ilha de Marajó). Revista Brasileira de Geografia, Rio de Janeiro, v. 18, n. 3, p. 89-123, 1956.

SANTOS, M. Ituberá, porto cacaueiro rejuvenescido pela indústria. Anais da Associação dos Geógrafos Brasileiros, São Paulo, v. 10, tomo 1, p. 119-131, 1958.

SCHMIDT, C. B. Alguns aspectos da pesca no litoral paulista. São Paulo: Secretaria da Agricultura, 1948.

SETTE, H. Aspectos da atividade pesqueira em Pernambuco. Anais da Associação dos Geógrafos Brasileiros, São Paulo, v. 11, tomo 1, p. 235-255, 1959. 